\title{
O DIREITO À ALIMENTAÇÃO DE CRIANÇAS E ADOLESCENTES: UMA DISCUSS ̃̃O ACERCA DO PAPEL DOS PODERES DO ESTADO E DA SOCIEDADE CIVIL EM PROL DA CONCRETIZAÇÃO
}

\author{
THE RIGHT TO FOOD IN CHILDREN AND ADOLESCENTS: A \\ DISCUSSION ABOUT THE ROLE OF THE POWERS OF THE STATE AND \\ CIVIL SOCIETY FOR THE IMPLEMENTATION
}

\author{
Aline Taiane Kirch $^{1}$ \\ Lívia Copelli Copatti ${ }^{2}$
}

\begin{abstract}
Sumário: 1. Introdução. 2 Proteção jurídica do direito à alimentação da criança e do adolescente 2.1 A proteção do direito à alimentação de crianças e adolescentes nos âmbitos nacional e internacional. 3 O direito à alimentação sob o viés da proteção integral. $3.1 \mathrm{O}$ direito à alimentação. 4 A problemática da efetivação do direito fundamental à alimentação de crianças e adolescentes. 4.1 A discussão sobre a efetivação dos direitos fundamentais sociais. 4.2 O direito à alimentação e sua efetivação: problemática e medidas para solução
\end{abstract}

Resumo: A alimentação é um direito fundamental por força da Emenda Constitucional 64/2010 e está previsto no Estatuto da Criança e do Adolescente. A abordagem deste texto inicia no viés da explanação da proteção normativa de tal direito, bem como de qual é o significado do direito à alimentação adequada e da segurança alimentar, e de suas importâncias para as crianças e os adolescentes. Na sequência assume importância a análise de que no Brasil a fome, a desnutrição e a insegurança alimentar são grandes problemas sociais em razão da falta de distribuição equitativa da terra e dos alimentos, das desigualdades regionais, sociais e econômicas do país, pela falta de uma economia sustentável e de uma educação alimentar sadia. Todavia essa realidade pode ser revertida através da execução de políticas públicas, ações da sociedade civil, incentivo a agricultura familiar, a reinvindicação judicial do direito à alimentação e da implementação de uma economia sustentável. Palavras-chave: Alimentação adequada. Criança e adolescente. Segurança alimentar.

\begin{abstract}
The alimentation is a fundamental right because of the Constitutional Amendment 64/2010 and is foreseen in the Child and Adolescent Statute. The approach of this text begins on bias explanation of rules of protection of such rights, as well as what is the meaning of the right to adequate feeding and food security, and their importance to children and adolescents. Following assumes importance the analysis that in Brazil the hunger, malnutrition and food insecurity are major social problems because of the lack of equitable distribution of land and food, regional, social and economic inequalities of the country, the lack of a sustainable economy and healthy food education. However this situation can be reversed through the implementation of public policies, actions of civil society, encouraging farming family, the claim in court of the right to alimentation and the implementation of a sustainable economy.
\end{abstract}

Keywords: Proper nutrition. Child and adolescente. Food safety.

\section{INTRODUÇÃO}

O tema do respectivo trabalho volta-se para o direito à alimentação de crianças e adolescentes no Brasil, tendo como problema tal direito e o papel dos poderes do Estado e da sociedade civil para a sua efetivação.

Tem-se como objetivos a exposição da proteção jurídica do direito à alimentação da criança e do adolescente, a análise do direito à alimentação sob o viés da Teoria da Proteção Integral e a visualização da problemática da efetivação do direito fundamental à alimentação de crianças e adolescentes, apontando-se possíveis soluções.

A cerca da proteção jurídica do direito à alimentação da criança e do adolescente o texto fará uma esboço sobre a proteção de tal direito, nos âmbitos da legislação nacional e internacional adotada pelo Brasil. Posteriormente, tratar-se-á do direito à alimentação sob o

\footnotetext{
${ }^{1}$ Mestranda em Direito e graduada em Direito pela Imed - Faculdade Meridional. Pós-graduanda em Direito Processual Civil pelo Complexo Educacional Damásio de Jesus. Advogada.

${ }^{2}$ Doutoranda em direito pela Universidade Estácio de Sá - Unesa. Mestre em Direito pela Universidade de Santa Cruz do Sul - UNISC. Graduada em Direito pela Universidade Regional Integrada do Alto Uruguai e das Missões, URI Campus de Erechim. Advogada. Professora na Faculdade Meridional - IMED em Passo Fundo.
} 
viés da proteção integral da criança e do adolescente, com base nos princípios que norteiam tal teoria.

Por conseguinte, será observada a problemática do direito à alimentação no cenário brasileiro, seguido da explanação sobre a efetivação dos direitos fundamentais sociais, que tem como base a dignidade da pessoa humana.

Enfim, ao tratar da efetivação do direito à alimentação, serão discutidas quais as medidas cabíveis para a sua concretização. O enfoque será na efetivação do direito à alimentação adequada da criança e do adolescente, visualizando o que vem sendo aplicado no país e o que ainda precisa ser implementado.

Tem-se como hipótese que o Brasil apresenta uma gama de princípios e normas para a proteção do direito à alimentação, tanto a nível geral, quanto em especial à criança e ao adolescente. Ainda, que no país há violações ao direito à alimentação e que estas afetam crianças e adolescentes, bem como a hipótese de que existem ações para a promoção do direito à alimentação, mas que, no entanto, ainda não contemplam a todos. A última hipótese levantada é de que é possível a criação e ampliação de medidas de combate á fome e de promoção do direito à alimentação adequada.

Para a realização deste trabalho utiliza-se o método de pesquisa dialético e as técnicas de pesquisa bibliográficas e documentais. A seguir, será possível obter uma concepção mais clara a respeito do desenvolvimento desta pesquisa que não visa esgotar o tema.

\section{PROTEÇÃO JURÍDICA DO DIREITO À ALIMENTAÇÃO DA CRIANÇA E DO ADOLESCENTE}

Assim como qualquer pessoa humana, a criança e o adolescente gozam de direitos naturais, bem como de direitos previstos em lei, na Constituição e nas declarações e tratados internacionais. Entretanto, diante da sua situação peculiar de pessoa em desenvolvimento, torna-se necessário a criação de documentos e instrumentos para a construção da proteção integral da criança, as quais são existentes em nível mundial, interamericano e nacional, dos quais, se fará um pequeno esboço no presente trabalho.

Os direitos da criança surgiram no contexto internacional através da Declaração de Genebra dos Direitos da Criança, em 1924, a qual não elenca direitos, mas princípios, podendo-se referir os seguintes: de desenvolvimento material e espiritual, de receber auxílio diante da fome, da enfermidade, de incapacidade, da orfandade e do abandono, de capacitação e formação para a vida, de proteção contra qualquer forma de exploração e de relacionar-se em uma cultura de fraternidade (ORGANIZAÇÃ̃O DAS NAÇÕES UNIDAS, 1924, grifo nosso) .

O direito à alimentação é essencial para a contemplação do exercício pleno do direito à vida e à saúde de qualquer ser humano. É por isso e tendo em vista que a criança, "em decorrência de sua imaturidade física e mental precisa de proteção e cuidados especiais" (ORGANIZAÇÃO DAS NAÇÕES UNIDAS, 1959) que a Declaração dos Direitos da Criança proclama que as crianças tem direito à alimentação adequada.

A Convenção Internacional dos Direitos da Criança acorda que o combate à desnutrição, através de fornecimento de alimentos nutritivos e de água potável, é uma das medidas em especial que os Estados devem tomar para que as crianças gozem do melhor padrão possível de saúde e dos serviços destinados ao tratamento das doenças e à recuperação da saúde (ORGANIZAÇÃO DAS NAÇÕES UNIDAS, 1989).

Outra medida que a Convenção Internacional dos Direitos da Criança entende necessária é assegurar que as crianças, pais e todos os setores da sociedade tenham conhecimento dos "princípios básicos de saúde e nutrição de crianças, as vantagens da 
amamentação, da higiene e do saneamento ambiental" (ORGANIZAÇÃO DAS NAÇÕES UNIDAS, 1989).

No âmbito do Sistema Interamericano de Proteção aos Direitos Humanos, tem-se como forma de proteção aos Direitos da Criança a sua inclusão na Convenção Americana de Direitos Humanos (Pacto San José da Costa Rica), de 1969. Em seu artigo 19 preceitua que: "Toda criança tem direito às medidas de proteção que a sua condição de menor requer por parte da sua família, da sociedade e do Estado." A partir da Convenção, a OEA realizou diversas resoluções e adoções de protocolos que reafirmam seu compromisso com a Proteção Integral da Criança (FUNDO DAS NAÇÕ ES UNIDAS PARA INFÂNCIA, 2012).

Além de ser reconhecida como um direito humano, a alimentação é um direito fundamental no Brasil por força da emenda constitucional 64/2010, que a incluiu no rol dos direitos sociais previstos no artigo $6^{\circ}$ da Constituição Federal, nos seguintes termos:

Art. $6^{\circ}$ São direitos sociais a educação, a saúde, a alimentação, o trabalho, a moradia, o lazer, a segurança, a previdência social, a proteção à maternidade e à infância, a assistência aos desamparados, na forma desta Constituição (BRASIL, 1988, grifo nosso).

O ápice da proteção dos direitos da criança e do adolescente na Constituição Federal é o artigo 227. É ele quem delega ao Estado, a sociedade e a família o dever pelo cumprimento dos direitos da criança e do adolescente e de colocá-los a salvo de toda forma de negligência, discriminação, exploração, violência, crueldade e opressão.

Tal artigo define como direitos da criança a alimentação e a dignidade, dentre outros direitos tão importantes quanto os recém citados (BRASIL, 1988). Admite também que atividades não governamentais atuem, assim como o Estado, para promover programas de assistência integral à saúde da criança, englobando meios de promoção dos direitos da criança e do adolescente deficiente, bem como da primeira infância.

Em harmonia com a Constituição, o Estatuto da Criança e do Adolescente determina que o direito à alimentação deve ser assegurado pela família, a comunidade, a sociedade e o Poder Público (BRASIL, 1990). A defesa do direito à alimentação em tal regimento legal não termina por aí. O ECA também determina, que o Poder Público, as instituições e os empregadores devem propiciar condições adequadas ao aleitamento materno (BRASIL, 1990).

Este direito deve ser concedido inclusive aos filhos de mães que cumprem medidas privativas de liberdade, tanto por força de determinação do ECA (BRASIL, 1990), quanto pela do artigo $5^{\circ}$, inciso L, da Constituição Federal (BRASIL, 1988). A criança permanece com a mãe até os seis primeiros meses de vida, para que se cumpra o período de alimentação exclusiva de leite materno, cumprindo assim também com o preceito constitucional de que a pena não pode ultrapassar a pessoa do condenado e da igualdade entre os filhos.

A promoção do direito ao aleitamento materno traz reflexos na legislação, como a Lei $n^{\circ}$ 11.770/ 2008 que deu origem ao Programa Empresa Cidadã. O programa é destinado à prorrogação da licença-maternidade para seis meses, mediante concessão de incentivo fiscal, e alterou a Lei $\mathrm{n}^{\mathrm{o}}$ 8.212, de 24 de julho de 1991, concedendo este direito às trabalhadoras da Administração Pública (BRASIL, 2008).

A promoção do direito à alimentação adequada inclui a garantia de alimentação pré e pós natal da genitora (artigo $8^{\circ}$, parágrafo terceiro do ECA, 1990). Isso porque, o direito à alimentação da criança perpassa pela efetivação do direito à alimentação da gestante e da nutriz.

Além do exposto, o ECA afirma novamente que crianças e adolescentes gozam do direito à alimentação, uma vez que são sujeitos de todos os direitos fundamentais inerentes à pessoa humana e da proteção integral, conforme o seu artigo $3^{\circ}$ (BRASIL, 1990). 


\section{O DIREITO À ALIMENTAÇÃO SOB O VIÉS DA PROTEÇÃO INTEGRAL}

No Brasil e no mundo houve um gradativo processo histórico para o reconhecimento da criança e do adolescente como pessoas em caráter de desenvolvimento e o afastamento do entendimento de que se tratavam de "adultos em miniatura" (CUSTÓDIO, 2009). Tal processo também foi paulatino no reconhecimento de que esta categoria é formada por sujeitos de direitos.

Com o objetivo de superar as sequelas deixadas pelo período da ditadura militar, a Constituição Federal de 1988 é o marco do estado democrático de direito no país, assumindo o compromisso com a dignidade da pessoa humana, com os direitos humanos e com os direitos fundamentais.

Ela foi a primeira Constituição do Brasil a adotar a Teoria da Proteção Integral como forma de proteção ao direito da criança e do adolescente e em respeito a sua condição de pessoa em desenvolvimento, preconizada em documentos internacionais. Refere em seu artigo $5^{\circ}$ que todos são iguais perante a lei, sem distinção de qualquer natureza (BRASIL, 1988). Dessa forma a criança e o adolescente, como sujeitos de direitos, estão sob o manto de todas as garantias e direitos elencados na Carta Magna.

Como referido, a criança e o adolescente estão sob o aparato da Teoria da Proteção Integral, que é regulamentada no Brasil por meio do Estatuto da Criança e do Adolescente de 1990. É através dela que a família, a sociedade e o Estado se tornam responsáveis em priorizar a efetividade dos direitos da criança e do adolescente. Tais direitos são tantos os próprios de pessoa em caráter de desenvolvimento, quanto àqueles inerentes a qualquer ser humano, na esfera dos direitos fundamentais e dos direitos humanos (COPATTI, 2011).

A Teoria da Proteção Integral é formada pela concepção de que todas as crianças e adolescentes são sujeitos de direitos. Aplica ao ordenamento jurídico brasileiro suas regras, valores e princípios para a garantia dos direitos da criança e do adolescente e para a criação de meios de efetivação. Estes direitos estão inseridos não somente no âmbito jurídico, mas também no âmbito social, político e moral, sendo que por eles todos são responsáveis. Para tanto, é essencial o respeito a determinados princípios.

Assim, tal tópico visa realizar uma breve conceituação dos princípios da Teoria da Proteção Integral de maior predominância no tocante ao direito à alimentação adequada de crianças e adolescentes. Deve-se ressaltar que todos os princípios da teoria são importantes, mas existe uma tríade principiológica basilar que é fundamental e norteadora de todos os demais princípios e dos direitos da criança e do adolescente, formada pelo Princípio da Proteção Integral da Criança e do Adolescente, pelo Princípio da Prioridade Absoluta e pelo Princípio do Interesse Superior da Criança.

Iniciando pelo Princípio da Proteção Integral da Criança e do Adolescente, este consiste no complexo de direitos inerentes à condição exclusiva da criança e do adolescente, que visa garantir o desenvolvimento integral destes sujeitos de direitos (CONANDA, 2010). Trata-se de um princípio constitucional previsto no artigo 227 da Carta Magna.

O Princípio da Proteção Integral fundamenta o ECA, como demonstrado no artigo primeiro deste, bem como é esmiuçado no artigo terceiro do mesmo (BRASIL, 1990). Assim, este é o mais importante de todos os princípios dos direitos da criança e do adolescente, pois abrange aos demais e é a base da Teoria da Proteção Integral.

Por ele o Estado realiza suas intervenções positivas e negativas na vida da família, da criança e do adolescente, como por exemplo, a prestação de saúde por meio do Sistema Único de Saúde, programas como o Bolsa Família, o fornecimento de merenda escolar nas escolas públicas, entre outras ações que visam dar prioridade na efetivação aos direitos da criança e do adolescente. 
O Princípio da Prioridade Absoluta encontra-se no artigo 227 da Constituição Federal e tem por objeto garantir a criança e ao adolescente a prioridade nas ações do Estado, da sociedade, da comunidade e da família. Ou seja, a efetivação dos direitos da criança e do adolescente tem caráter de prioridade sobre todas as áreas de atuação destes entes (BRASIL, 1988).

A prioridade não se exaure ao socorro, proteção, atendimento, destinação de recursos públicos e formulação de políticas públicas previstos no parágrafo único do artigo $4^{\circ}$ do ECA (BRASIL, 1990). Também engloba a primazia na efetivação dos direitos peculiares a condição de criança ou adolescente, bem como dos direitos fundamentais, como preceitua a primeira parte do artigo terceiro do ECA ao referir que "a criança e o adolescente gozam de todos os direitos fundamentais inerentes à pessoa humana, sem prejuízo da proteção integral".

O Princípio do Melhor Interesse da Criança, ou Princípio do Interesse Superior da Criança, é previsto no artigo 100, inciso IV do ECA, no título referente às medidas de proteção. Não obstante, esse princípio se aplica a todas as crianças e adolescentes, pois encontra-se implícito na Constituição Federal e no ECA quando verificados seus fundamentos, garantias e valores, principalmente no tocante a dignidade da pessoa humana. Além disso, o princípio está previsto expressamente no artigo $3^{\circ}$ da Convenção Sobre os Direitos da Criança, da qual o Brasil é signatário (ORGANIZAÇÃO DAS NAÇÕES UNIDAS, 1989).

Após a exposição destes três importantes princípios, faz-se importante para o desenvolvimento do trabalho destacar os demais princípios que tem maior influência sobre o direito à alimentação da criança e do adolescente. Inicia-se com o Princípio da Descentralização Político-Administrativa, que está previsto no artigo 204, inciso I da Constituição Federal e reconhece a autonomia das três entidades políticas: União, Estados e Municípios, que agem dentro de suas competências (BRASIL, 1988).

Reconhece também a responsabilidade de ambas, que devem agir em articulação conjunta de ações, consideradas aqui as que têm relação com os direitos da criança e do adolescente. Da mesma forma, aplica-se aos Poderes Executivo, Legislativo e Judiciário, bem como a todos os cidadãos (COPATTI, 2011).

O Princípio da Participação Política e Controle Social consiste na participação do povo de forma organizada, para a reivindicação e produção de políticas públicas e sociais, através da criação de Conselhos Gestores de Políticas Públicas e dos mecanismos de participação direta (CONANDA, 2010). A maior participação política e de controle social dos direitos da criança e do adolescente é realizada pelos Conselhos de Direitos da Criança e do Adolescente (COPATTI, 2011).

Por fim, o Princípio da Ênfase nas Políticas Sociais Básicas, que se dá através do Princípio da Intersetorialidade e Trabalho em Rede. Isso porque o reconhecimento da necessidade, a elaboração e aplicação de políticas públicas e sociais voltadas à criança e o adolescente, que estão protegidos pelo Princípio da Prioridade Absoluta, devem ser efetuadas através do trabalho distribuído em setores e sob um sistema de rede, não afastando a responsabilidade maior do Estado (CONANDA, 2010).

Estes princípios conjugam a Teoria da Proteção Integral. Suas concretizações são verdadeiros desafios perante as mazelas sociais do país. Visualizam-se diversas atividades do poder público e das organizações sociais e religiosas para suas efetivações, em contraponto, as omissões pelos que também são responsáveis pelas suas efetivações fazem com que ainda não possa se falar no pleno respeito à Teoria da Proteção Integral e dos Direitos da Criança e do Adolescente.

O direito à alimentação é irrefutável e significa a própria efetivação do direito à vida. Na lição de Valente o direito à alimentação é o: 
Direito de acesso aos recursos e meios para produzir ou adquirir alimentos seguros e saudáveis que possibilitem uma alimentação de acordo com os hábitos e práticas alimentares de sua cultura, de sua região ou de sua origem étnica (VALENTE, 2002, p. 38).

A alimentação adequada para crianças e adolescentes é sinônimo de garantia de nutrição e alimentos suficientes que sejam saudáveis, seguros e de qualidade. Além disso, deve permitir que desfrutem da amamentação, do prazer de saborear variados alimentos e proporcionar a vivência da cultura e das tradições da qual a criança e o adolescente fazem parte. A alimentação adequada proporciona às crianças e aos adolescentes o exercício da cidadania, a qualidade de vida e a harmonia com a natureza.

Para que o direito à alimentação adequada de todas as pessoas, inclusive das crianças e adolescentes do país seja uma realidade, é imprescindível que exista segurança alimentar. Segundo a FAO a segurança alimentar:

Existe quando todas as pessoas em todos os momentos têm acesso físico e econômico a alimentos suficientes, seguros e nutritivos para satisfazer as suas necessidades dietéticas para desenvolver uma vida ativa e saudável (ORGANIZAÇÃO DAS NAÇÕES UNIDAS PARA A ALIMENTAÇÃO E AGRICULTURA, 2013).

A segurança alimentar é um dever do Estado e da sociedade (VALENTE, 2002). Na falta de seu cumprimento se instala a insegurança alimentar que segundo a FAO, pode ocorrer "devido à indisponibilidade de alimentos, poder aquisitivo insuficiente ou inadequada utilização do mesmo para a família" (ORGANIZAÇÃO DAS NAÇÕES UNIDAS, 2013).

Nesse contexto, o direito à alimentação consiste em muito mais do que uma pessoa ter o que comer. Não há o exercício do direito à alimentação se o indivíduo come, mas tem uma alimentação de baixa ou sem qualidade, quando o alimento é escasso, quando não houver a certeza de que será possível realizar a próxima refeição, tenha que abrir mão de outra necessidade importante para se alimentar ou ainda quando que para conseguir alimento tenha que passar por situações inadequadas ou degradantes como, por exemplo, o trabalho infantil, o trabalho escravo, a prostituição, alimentar-se do que está no lixo ou estar em situação de pedinte (MENEZES, 2005).

\section{A PROBLEMÁTICA DA EFETIVAÇÃO DO DIREITO FUNDAMENTAL À ALIMENTAÇÃO DE CRIANÇAS E ADOLESCENTES}

O Mapa da Fome demonstra que a desnutrição, a fome e a falta de segurança alimentar são grandes mazelas sociais. Segundo o Mapa, no Brasil o número de pessoas subnutridas entre 2010 e 2012 foi de 13 milhões (ORGANIZAÇÃO DAS NAÇÕES UNIDAS, 2013). Este índice aponta que o direito à alimentação merece maior atenção pelo Estado e pela sociedade civil, principalmente quando entre as vítimas da negação de tal direito estão crianças e adolescentes.

Estudos demonstram que quando mais cedo se instala a desnutrição no ser humano, mais grave serão as consequências. Valente explica que:

A desnutrição, em suas manifestações mais graves, pode ter impacto irreversível sobre o tamanho, a estrutura orgânica, a diferenciação das funções, o desenvolvimento, a maturação fisiológica e funcional do Sistema Nervoso Central. Entre estas podemos citar alterações na multiplicação das células gliais, no processo de mielinização, na maturação de enzimas, no aumento das conexões sinápticas, na diferenciação das terminações nervosas, na quantidade de DNA, RNA e proteínas existentes. Tais lesões serão mais graves quando a desnutrição se instalar nas fases 
mais precoces do desenvolvimento do SNC, que se acelera no segundo trimestre da gestação e está praticamente concluído ao final dos 24 meses de vida.

Assim, a falta de alimentação adequada da gestante no último semestre da gravidez e a desnutrição nos primeiros dois anos de vida são responsáveis por eventuais alterações orgânicas e funcionais irreversíveis do SNC, que serão tanto mais graves quanto mais longo, sério, e precoce for o episódio de desnutrição (VALENTE, 2002, p. 30).

A fome e a desnutrição afetam o crescimento, a saúde, o humor e a cognição da criança (VALENTE, 2002). A falta de alimentação constante e adequada durante o dia ocasiona a diminuição de glicose no sangue o que acarreta em dificuldade de concentração de crianças e adolescentes nas aulas (VALENTE, 2002). Nesse sentido o fornecimento de merenda escolar é de suma importância para a nutrição e o rendimento escolar da criança e do adolescente. Em muitos casos, é somente na escola que a criança obtém um alimento nutritivo e saudável.

Embora o Brasil seja um país de grande área de terras produtivas e capaz de produzir variados alimentos, há falta de distribuição equitativa da terra e da comida. No país, as desigualdades regionais, sociais e econômicas são as causas da pobreza e da fome.

Sabe-se que a quantidade de alimentos produzidos seria suficiente para garantir o direito à alimentação adequada de todos. Segundo dados da FAO, no mundo se produz comida suficiente para 12 bilhões de seres humanos (ORGANIZAÇÃO DAS NAÇÕES UNIDAS, 2013), ou seja, o dobro da população global, mas a ganância de governantes e da sociedade civil gera a fome e a miséria.

O crescimento econômico acaba por se tornar um fim absoluto, ao invés de ser um meio sustentável para o bem estar do ser humano. "A fome e a desnutrição estão dentro do processo mais amplo de exclusão social" (VALENTE, 2002, p. 37), pois o faminto e o desnutrido são privados de terem qualidade de vida, saúde e o acesso a quaisquer outros direitos, obrigados a viver em um ciclo vicioso de miséria.

As desigualdades e a falta de distribuição equitativa de alimentos também geram de um lado o sobrepeso e a obesidade infantil, e de outro a fome e a desnutrição. Em todo o país, crianças manifestam doenças ligadas à alimentação, quer porque estejam em um extremo (sobrepeso), quer porque estejam em outro (subnutrição). Isso significa que as desigualdades, a ausência de informação e educação para uma alimentação saudável são problemas no direito à saúde de todos.

Se por um lado há falta de alimentos, por outro há a insegurança de se estar consumindo um alimento saudável. A prática atualmente utilizada por indústrias, produtores na agricultura e na agropecuária de utilização de hormônios, agrotóxicos, transgênicos, conservantes, enfim, insumos químicos acarretam em uma série de problemas para a saúde dos seres humanos.

Doenças como as cardiovasculares, diabetes, câncer, obesidade entre outras se manifestam na população, inclusive nas crianças e adolescentes, que a algumas décadas atrás, raramente eram vítimas de tais enfermidades. Cada vez mais é possível visualizar também que crianças que estão em seu peso ideal manifestam algum tipo de anemia, visto que, por mais que tenham acesso aos alimentos, estes não são nutritivos.

Os alimentos tipicamente brasileiros (e extremamente nutritivos) como o arroz, o feijão, a carne, bem como as frutas e os vegetais estão cada vez mais inacessíveis aos pobres, tanto para os que vivem na área urbana como para os que vivem na área rural. Isso acaba dando espaço para alimentos pouco nutritivos que tem excesso de carboidrato, gordura e açucares como refrigerantes e produtos industrializados que estão mais em conta para o orçamento da família pobre brasileira. Com isso crianças e adolescentes tem uma baixa qualidade nutritiva na sua alimentação. Atualmente, crianças e adolescentes do campo e da 
cidade estão condenadas a uma alimentação pobre de nutrientes, pouco segura e de baixa qualidade (IBASE, 2011).

Pela peculiaridade da criança e do adolescente de pessoa em desenvolvimento, especificamente os direitos fundamentais destes no Brasil estão previstos no Título III do Estatuto da Criança e do Adolescente que se dão através de políticas públicas e devem ser sempre aplicados de forma cumulativa com as demais normas para a efetivação da Teoria da Proteção Integral.

A Constituição Federal de 1988 assumiu compromisso com a dignidade da pessoa humana da qual a criança e o adolescente são merecedores. Cabe a família, a comunidade, a sociedade e o Estado a efetivação desse princípio, por meio do cumprimento dos direitos da criança e do adolescente aos quais lhe incumbem, de forma a proteger com prioridade esses sujeitos de direitos.

Dias afirma que:
A supremacia da dignidade da pessoa humana está lastreada no princípio da igualdade e da liberdade, grandes artífices de um novo Estado Democrático de Direito que foi implantado no País. Houve o resgate do ser humano como sujeito de direito, assegurando-lhe, de forma ampliada, a consciência da cidadania. $\mathrm{O}$ constituinte de 1988 consagrou, como dogma fundamental, antecedendo a todos os princípios, a dignidade da pessoa humana (CF $1^{\circ}$, III), impedindo assim a superposição de qualquer instituição à tutela de seus integrantes. Foram eliminadas injustificáveis diferenciações e discriminações que não mais combinam com uma sociedade democrática e livre (DIAS, 2011, p. 41).

Ao tratar do direito à alimentação é indispensável a concepção de que a pessoa humana, e aqui tratando especificamente, a criança e o adolescente, possuem um direito não somente de não passar pela condição da fome, mas sim o de uma alimentação adequada. A importância de tal direito humano é de tamanha grandeza que ao ser vinculado a Constituição como um direito fundamental, demonstra a imprescindibilidade de tal direito, de tal forma que recebe uma proteção procedimental contra o eventual risco de negligência, assim como de limite ao Estado na elaboração de políticas públicas (SODRÉ, 2013, p.32).

Sendo assim, ao ser definido como um direito fundamental social, o direito à alimentação tem assegurada sua exigibilidade imediata diante do Estado e da sociedade civil. De acordo com Sodré, tal exigibilidade gera perante tais entidades:

[...] um dever prestacional, tendo-se por hipótese que sim, que a nota de fundamentalidade recebida por um Direito Humano quando de sua inserção no catálogo de Direitos Fundamentais de uma comunidade, em especial daquela que proclama a dignidade da pessoa humana como princípio fundante de seu ordenamento jurídico, traz, como consequência, a imediata exigibilidade do direito frente a esta comunidade e ao Estado, gerando um dever de prestação (SODRÉ, 2013, p. 14).

É preciso o espírito de cooperação, e de trabalho em rede para a efetivação dos direitos da criança e do adolescente. Entretanto, para que isso aconteça, é necessário que os responsáveis assumam a sua posição de protagonistas, ressaltando-se que a efetivação dos direitos da criança e do adolescente deve primeiramente ser realizada pela família, que deve ser valorizada, com o comprometimento dos pais para com seus filhos. Com isto, supera-se a concepção de que se deve ficar aguardando a atuação única do Estado agindo, então, de forma solidária com este, para que assim haja a supressão da concepção de Estado-pai existente no Brasil.

Conjuntamente, com a família, a sociedade deve agir no apoio, bem como quando esgotadas todas as possibilidades de atuação familiar para a efetivação dos direitos da criança 
e do adolescente. A sociedade deve tornar-se ativa na proteção dos direitos da criança, por meio de atos e organizações da sociedade civil, agindo de forma solidária com a família e o Estado, bem como na reivindicação dos direitos da criança e do adolescente e, principalmente, participando nas definições das prioridades e diretrizes.

Por fim o Estado, cumprindo com o seu dever de agir de forma ativa para a realização da dignidade da pessoa humana, suprindo as deficiências residuais da família, promovendo e protegendo direitos, mas também dando formação para que a criança, a família e a sociedade possam desenvolver-se para a emancipação humana.

É importante, no contexto presente, desenvolver a análise relativa ao direito à alimentação e sua efetivação, proporcionando uma discussão sobre a problemática e algumas medidas que podem contribuir para tanto, o que realiza-se na sequência.

Para que situações de violação do direito à alimentação sejam erradicadas é preciso uma série de mudanças e ações, que devem ser construídas tanto pelo Estado (Executivo, Legislativo e Judiciário), como pelo Ministério Público (como defensor dos direitos constitucionais) e sociedade civil.

É de suma importância a criação de políticas públicas voltadas ao fornecimento de alimentos e de incentivos sustentáveis para o estímulo da produção própria e para que as pessoas tenham poder aquisitivo para adquirir seus alimentos.

Atualmente o Brasil conta com o Plano Brasil Sem Miséria para o enfrentamento da pobreza, objetivando aumentar a renda e as condições de bem-estar das pessoas. Um de seus meios para tanto é o uso do Programa Bolsa Família, criado no Programa Fome Zero, o qual objetiva implementar políticas públicas e acesso á alimentação através de quatro diretrizes: acesso à alimentação, geração de renda, fortalecimento da agricultura familiar e articulação, mobilização e controle social (BRASIL 2013).

O Programa Bolsa Família tem como finalidade unificar as políticas de transferência de renda do Governo Federal que eram vigentes antes de sua criação, sendo elas: o Programa Nacional de Renda Mínima vinculado à Educação - Bolsa Escola, o Programa Nacional de Acesso à Alimentação - PNAA, o Programa Nacional de Renda Mínima vinculada à Saúde Bolsa Alimentação e o Programa Auxílio-Gás, bem como o Cadastramento Único do Governo Federal (BRASIL, 2004).

Trata-se de uma ação de transferência de renda condicionada e que apresenta dois objetivos principais: "o combate à fome, à miséria e à exclusão social e a promoção da inclusão social, voltada à emancipação das famílias pobres e extremamente pobre" (IBASE, 2011, p. 29). O programa transfere renda às famílias em situação de pobreza para que possam ter acesso à saúde, educação, alimentação e assistência social (BRASIL,2013).

No tocante ao requisito de condicionalidade do Programa Bolsa Família, existem posicionamentos tanto no sentido de crítica, como a favor de tais exigências. A crítica se dá no tocante a legitimidade de tal condição, visto que se refere a um direito fundamental social, e sendo assim, não podem ser exigidas condições para a sua efetivação (SENNA, et. al, 2007). Por outro lado, para o Ministério do Desenvolvimento Social e Combate à Fome, as condicionalidades são importantes na medida em que proporcionam a inserção das famílias nas políticas de saúde e educação, bem como a ruptura com o ciclo reprodutivo da pobreza (IBASE, 2011. SENNA, et. al, 2007). Um ponto a favor da condicionalidade é que a progressão escolar e a proporção de crianças e adolescentes até catorze anos beneficiados pelo programa na rede de ensino é maior comparada aos sujeitos não beneficiados de mesma faixa etária (AVALIAÇÃO DE IMPACTO DO BOLSA FAMÍLIA, 2009)

Tal política pública é dividida entre avanços e irregularidades. O Bolsa Família conseguiu concretizar a muitos o acesso mínimo aos direitos sociais recém citados, mas também apresenta o problema da inclusão de famílias que não se enquadram nos requisitos necessários e a exclusão de famílias que necessitam dessa política pública. A falta de 
conscientização por parte de alguns gestores públicos de que o programa não é um favor prestado que possa ser utilizado para fins eleitoreiros, mas sim um direito, também é um problema (LANE, 2010).

De acordo com a Escala Brasileira de Insegurança Alimentar (EBIA):

As famílias beneficiadas, de forma geral, gastam com alimentação, aproximadamente, $56 \%$ da renda domiciliar. Para as famílias em situação de insegurança alimentar grave, o percentual chega a 70\%. Os dados mostram que são justamente as famílias mais vulneráveis à fome aquelas que comprometem a maior parte de seu orçamento doméstico com alimentação e que, portanto, mais sentem o impacto de crises que levam ao aumento no preço dos alimentos (BRASIL, 2014).

Apesar de o Programa Bolsa Família ainda não conseguir alcançar a todos que dele necessitam, ele apresenta vantagens em sua forma, pois a transferência monetária direta do benefício é benéfico na diminuição dos custos administrativos do programa e na resistência à incidência de fraudes e desvios de recursos (LAVINAS, 2000, p. 68). Além disso, apresentase mais oportuno, pois permite a liberdade de escolha dos produtos, quando comparada à clássica modalidade de distribuição do benefício in natura (LAVINAS, 2000, 68).

É imprescindível que políticas públicas sejam desenvolvidas, e as já existentes aprimoradas para o combate a fome de crianças e adolescentes através de programas para a nutrição e segurança alimentar. Necessita-se trabalhar vários setores para atingir o direito à alimentação como a saúde, o saneamento básico, a educação, a agricultura e a economia.

De mesma importância é a atuação da sociedade civil para o combate a fome. A atuação da ABRANDH (Ação Brasileira pela Nutrição e Direitos Humanos), de Ong's, das Cáritas, da Pastoral da Criança, as mobilizações, os movimentos, as associações, a pressão junto ao legislativo, a reivindicação, o acompanhamento e avaliação de ações e políticas públicas e as ações de responsabilidade social de empresas são importantes áreas de atuação da sociedade civil.

No mesmo sentido, a parceria entre governo e sociedade civil é crucial para a instalação da segurança alimentar. A sociedade precisa se envolver mais com a problemática da efetivação do direito à alimentação de todos, principalmente da criança e do adolescente, e o governo ouvir e executar as demandas que a sua sociedade necessita. Enfim, é necessário o diálogo e atuação conjunta entre sociedade civil e governo.

A agricultura familiar é forte instrumento do direito à alimentação. A área rural sofre com a fome e com a falta e incentivo para permanecer no campo. Os adolescentes não veem motivação para permanecer no cultivo da terra na fase adulta, pois não encontram o acesso a direitos mínimos como o trabalho, a educação, a saúde, saneamento básico, assistência social e a alimentação. $\mathrm{O}$ êxodo rural muitas vezes agrava ainda mais a situação de famílias que vão para a cidade sem encontrar ali o mínimo de estrutura necessária.

É imprescindível a implementação de mais políticas públicas e de efetivação dos direitos sociais nas áreas rurais para que haja mais qualidade de vida no campo e para que o jovem sinta-se motivado a permanecer na área rural. Para a ampliação do acesso a alimentação é preciso o apoio à agricultura familiar, o acesso a terra e condições para nela produzir, o estimulo à produção de alimentos básicos e a promoção da agricultura ecológica sustentável (VALENTE, 2002).

$\mathrm{O}$ incentivo a agricultura familiar e ao trabalho por meio de cooperativas bem articulado e sustentável fomenta a segurança alimentar das famílias do campo, a qualidade de alimentos e a geração de renda, trazendo por consequência alimentos seguros e segurança alimentar para o consumidor da cidade. 
O direito fundamental à alimentação tem sua essência na realização pelo Estado por meio de políticas adequadas e conforme as necessidades próprias da sociedade e dos públicos mais necessitados.

Ocorre que, em caso de ausência de tais políticas, ou, mesmo quando existentes não atingem o objetivo proposto, surgem direitos subjetivos à alimentação e desta forma, pode-se utilizar de outros instrumentos para a sua garantia como é o caso das ações judiciais que destinam-se a fazer cumprir o direito fundamental à alimentação.

Leivas (2009), ao tratar sobre o tema da exigibilidade do direito à alimentação adequada no Seminário internacional "A exigibilidade do Direito Humano à Alimentação Adequada e o Sistema Nacional de Segurança Alimentar e Nutricional”, realizado em outubro de 2009, explica:

O que significa a exigibilidade? No conceito jurídico, exigibilidade está ligada à eficácia. Em primeiro lugar o reconhecimento do DHAA implica na obrigação do Poder Executivo em estabelecer políticas públicas que garantam este direito. Em segundo lugar, uma obrigação do Poder Legislativo de criação de leis que garantam o DHAA. Em terceiro lugar, o princípio da proibição do retrocesso social. Esse princípio está atualmente sendo construído no direito brasileiro, com uma grande influência do direito europeu, e prevê que quando garantido um certo patamar de realização de direitos sociais, na qual se inclui o DHAA, não poderá haver retrocesso, nem por ação ou omissão, do Poder Executivo nem do Poder Legislativo. E o Poder Judiciário seria o guardião desta proibição de retrocesso. Então, numa eventual mudança de linha de governo, poder-se-ia defender o patamar alcançado atualmente desse direito, com base no princípio da proibição de retrocesso social (LEIVAS, 2009. p. 53).

Sendo assim, a exigibilidade juricial do direito à alimentação é uma alternativa para a sua concretização (LANE, 2010). A respeito do assunto, Zimmermann, 2007, explica que:

O Poder Judiciário não tem como função elaborar políticas públicas, mas confrontar as políticas formuladas com os padrões jurídicos compatíveis, reenviando a questão aos órgãos estatais pertinentes (Executivo e Legislativo) para que elas sofram as modificações (ZIMMERMANN, in PIOVESAN. CONTI, 2207, p. 237).

Dessa forma, não cabe ao Poder Judiciário criar políticas públicas, mas tão somente "impor a execução daquelas já estabelecidas nas leis constitucional ou ordinárias" (KRELL, 2002, p. 42). Já ao Ministério Público, "órgão cujas atribuições incluem a proteção dos direitos humanos" (LANE, 2010, p. 172), cabe acionar a justiça.

Embora trate-se de um importante e forte instrumento para a efetivação do direito à alimentação, a exigibilidade jurídica de tal direito é uma ideia ainda pouco difundida no Brasil. Em pesquisa jurisprudencial e bibliográfica referente ao assunto fora encontrada apenas uma ação nesse sentido. Trata-se da Ação Civil Pública interposta pelo Ministério Público do estado de Alagoas, por meio das Promotorias de Infância e Juventude e o Ministério Público do Trabalho, em face do Município de Maceió.

A ação objetivava a elaboração e execução de políticas públicas para solucionar a violação dos direitos humanos, econômicos, sociais e culturais de crianças e adolescentes na Orla Lagunar de Maceió que se encontravam em situação abaixo da linha da pobreza e enfrentavam uma série de dificuldades para exercer seus direitos humanos mais fundamentais, como o de se alimentar. ${ }^{3}$

\footnotetext{
${ }^{3}$ Processo no 4.830/07. 28 ${ }^{\text {a }}$ Vara Cível da Capital - Infância e Juventude. Juiz de Direito: Fábio José Bittencourt Araújo. Julgado em 10 de setembro de 2007.
} 
A Ação Civil Pública baseou-se em pesquisa realizada pela ABRANDH através de exames e aplicação de questionários à comunidade. Entre as inúmeras violações à dignidade da Pessoa Humana destacam-se a existência de prostituição infantil, que iniciava partir dos 06 a 08 anos de idade, pelo valor de $\mathrm{R} \$ 0,30$ (trinta centavos), adolescentes que praticavam assaltos, pais que consumiam excessivamente álcool e drogas; infantes e jovens que estavam fora da escola por falta de transporte, além da deficiência na alimentação das crianças, que estaria comprometendo o desenvolvimento físico e intelectual das mesmas e o direito ao crescimento saudável. ${ }^{4}$

A Ação Civil Pública foi julgada parcialmente procedente pelo Tribunal de Justiça do Estado de Alagoas. Assim o Município de Maceió foi condenado a formar uma comissão multidisciplinar de profissionais para realizar perfil sócio-econômico das crianças e adolescentes da Orla Lagunar; oferecer condições adequadas para o funcionamento do Conselho Tutelar da Região, inclusive número telefônico gratuito (0800) para recebimento de denúncias; apresentar um cronograma de ampliação da rede de proteção à criança e ao adolescente; fornecer creche em horário integral e educação infantil, em quantidade suficiente para atender a população de 0 a 6 anos da referida comunidade bem como assegurar as matrículas de todas as crianças e adolescentes em idade escolar no ensino fundamental.

Vigna aponta que, com base no artigo 74 da Constituição Federal, é possível a atuação do Poder Judiciário no que concerne à execução dos orçamentos destinados à segurança alimentar, podendo, por exemplo, em ação judicial obrigar o Poder Executivo a repor ou aumentar os recursos para os programas já desenvolvidos (VIGNA, 2007).

É de absoluta necessidade que se implemente uma teoria da segurança alimentar nutricional sustentável como eixo para o desenvolvimento (VALENTE, 2002) e para que isso aconteça é imprescindível um crescimento econômico sustentável. Dessa forma garantir-se-á o direito fundamental à alimentação para as crianças e os adolescentes, gerando consequentemente maior qualidade de vida.

As iniciativas de desenvolvimento local devem incorporar entre seus elementos a garantia do direito à alimentação adequada (VALENTE, 2002). A construção da segurança alimentar e nutricional se constitui através da implementação do princípio básico de qualquer projeto de desenvolvimento local, qual seja, a garantia de que todos naquele espaço se alimentem bem. Esse deve ser um dos objetivos primários das organizações sociais que tenham como foco central o bem estar do ser humano (VALENTE, 2002).

De acordo com Valente, a partir daí ações podem ser tomadas, como:

\begin{abstract}
O desenvolvimento da reforma agrária, a produção urbana coletiva ou individual de alimentos, mecanismos de comercialização direta do produtor ao consumidor, políticas locais de abastecimento popular, ações de infraestrutura sanitária e saneamento, promoção de serviços de saúde orientados para pessoas e famílias em risco, fortalecimento de programas de alimentação coletiva, entre outros (VALENTE, 2002, p. 128).
\end{abstract}

Um pequeno exemplo de acordo com as ações acima levantadas seria a parceria de município e pequenos produtores rurais e cooperativas para a merenda escolar.

Sabe-se que é extremamente importante que todas as escolas públicas forneçam merenda escolar para os alunos. Nessa linha de raciocínio, o turno integral possibilita além de maior formação, a concretização de uma alimentação mais adequada para crianças, que fora da escola podem se encontrar em situação de vulnerabilidade social.

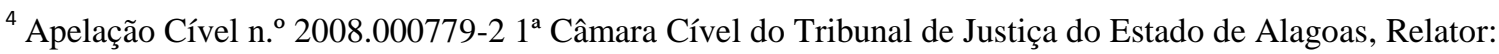
James Magalhães de Medeiros. Julgado em 25 de agosto de 2010.
} 
Dessa forma, é possível nesse espaço incentivar os pequenos agricultores. O Estado e os municípios podem adquirir alimentos para merenda produzidos nas pequenas propriedades rurais e nas cooperativas. O Programa de Aquisição de Alimentos (PAA) promove esta política. De acordo com o Ibase, 2011:

Ele articula os gastos públicos com alimentação à produção local da agricultura familiar, de modo que os programas que visam a garantir o direito humano à alimentação possam também assegurar mercado aos agricultores mais excluídos e gerar desenvolvimento local. Adquire alimentos diretamente do agricultor familiar para o abastecimento da Rede de Equipamentos Públicos de Alimentação e Nutrição, para a Rede Pública de Ensino, para a formação de Cestas de Alimentos e ainda para a formação de estoques públicos. Entre 2003 e 2010, foram adquiridos 3,1 milhões de toneladas de alimentos e investidos um total de R\$ 3,5 bilhões no Programa de Aquisição de Alimentos (IBASE, 2011, p. 43).

Esse é um dos meios de incentivo que pode ser ampliado para que os produtores rurais permaneçam com a policultura ao invés de partirem para a monocultura, como tem ocorrido há alguns anos. Como consequência, há maior produção e consumo de alimentos saudáveis, gerando um meio de economia sustentável aos pequenos agricultores dos municípios onde as escolas se encontram. Nesta linha, o Programa Nacional de Alimentação Escolar (PNAE), a partir de 2011:

[...] passou a exigir que, no mínimo, 30\% dos recursos financeiros repassados pelo Governo Federal para a alimentação escolar aos governos estaduais e municipais fossem utilizados com alimentos adquiridos diretamente da agricultura familiar, o que representa um novo mercado de, no mínimo, $\mathrm{R} \$ 900$ milhões anuais (IBASE, 2011, p. 46).

As merendeiras e cozinheiras poderiam receber cursos de aprendizados nutricionais e de técnicas de aproveitamento integral de alimentos. Hortas comunitárias ou cultivadas no ambiente escolar pelos alunos é uma pequena atitude que também poderia ser executada para garantir verduras e legumes saudáveis para uma comunidade.

Em estudo desenvolvido pelo Polis há a identificação de cinco grandes diretrizes para a promoção da segurança alimentar e nutricional no município. Essas cinco diretrizes consistem em:

\footnotetext{
1) Promover a produção rural e urbana e a comercialização de alimentos, realizadas em bases socialmente equitativas; 2) ampliar o acesso a uma alimentação de qualidade e regular as condições em que os alimentos são disponibilizados à população; 3) promover a educação alimentar e a organização dos consumidores na defesa dos seus direitos; 4) universalizar e assegurar a qualidade dos programas alimentares com caráter suplementar ou emergencial dirigidos a grupos populares específicos; 5) estimar a participação da sociedade civil na formulação e implementação da política de segurança alimentar e apoiar as iniciativas nãogovernamentais (MALUF, 2000, p. 46)
}

Através de ações e diretrizes realizadas pela sociedade civil e o Estado, bem como a existência de cooperação e parceria entre estes, é possível a concretização do direito à alimentação de todas as crianças e adolescentes do país. Produzem-se alimentos suficientes para a alimentação adequada de todos. Prova disso, por exemplo, é a atual doação de 25 mil toneladas de arroz do Brasil para Cuba (EXAME, 2012). As iniciativas do Estado e da sociedade civil vem colaborando para a diminuição da fome no Brasil. Entretanto este processo necessita ser muito mais célere e a segurança alimentar, um dos objetivos principais do governo. 


\section{CONCLUSÃO}

De acordo com o visualizado no trabalho, conclui-se que a alimentação adequada é um direito fundamental que se concretiza através da implementação da segurança alimentar. Conclui-se também que por meio da Teoria da Proteção Integral e do aparato de normativas protetivas e garantidoras de direitos, crianças e adolescentes são detentoras do direito à alimentação adequada, que assegure alimentos nutritivos, saudáveis e de fácil acesso.

Para tanto, observa-se, conforme o previsto, que esta concretização depende de ações tanto do Estado como da sociedade civil. Todavia, apesar do crescente desenvolvimento econômico, o direito à alimentação de crianças e adolescentes é violado no Brasil e merece maior atenção, visto que a insegurança alimentar e a alimentação inadequada geram problemas de saúde para crianças e adolescentes, riscos ao próprio direito à vida e um processo de marginalização e exclusão social.

Fora demonstrado que a violação do direito à alimentação ocorre devido à falta de distribuição equitativa dos alimentos, que é consequência das desigualdades sociais, regionais e econômicas, bem como por ser a alimentação, um direito de menor importância para alguns governantes. Inferiu-se também que os mais afetados por tal realidade são as crianças e os adolescentes.

A hipótese de que o Brasil apresenta uma gama de princípios e normas para a proteção do direito à alimentação, tanto a nível geral, quanto em especial à criança e ao adolescente fora confirmada no decorrer do trabalho, visto a exposição de variadas normas de âmbitos nacional, internacional e ainda, constitucional e infraconstitucional.

Fora reconhecida também a hipótese de que existem ações para a promoção do direito à alimentação, mas que, no entanto, ainda não contemplam a todos. Entretanto, visualizou-se a possibilidade da criação e ampliação de medidas de combate á fome e de promoção do direito à alimentação adequada.

Sendo assim, comprova-se a necessidade da implementação de uma teoria da segurança alimentar sustentável para o desenvolvimento social e humano. Entende-se que isto ocorre por meio de ações oriundas tanto do Estado como da sociedade civil, por meio de políticas públicas, da implementação de um crescimento econômico sustentável, pelo incentivo à agricultura familiar, pela exigibilidade judicial do direito à alimentação.

\section{REFERÊNCIAS}

BRASIL. Constituição da República Federativa do Brasil de 1988. Diário Oficial da União, Poder Legislativo, Brasília, DF, 5 out. 1988. Disponível em:

http://www.planalto.gov.br/ccivil_03/constituicao/constituicaocompilado.htm. Acesso em 10 de maio de 2013.

Documento preliminar para consulta pública, Construindo a Política Nacional dos Direitos Humanos de Crianças e Adolescentes e o Plano Decenal dos Direitos Humanos de Crianças e Adolescentes 2011 - 2020. CONANDA, 2010

Lei $\mathrm{n}^{\circ}$ 8.069, de 13 de julho de 1990. Dispõe sobre o Estatuto da Criança e do Adolescente e dá outras providências. Diário Oficial da União, Poder Executivo, Brasília, DF, 16 jul. 1990. Disponível em:

http://www.planalto.gov.br/ccivil_03/leis/18069.htm. Acesso em 10 de maio de 2013. 
. Lei no 11.770, de 09 de setembro de 2008. Cria o Programa Empresa Cidadã, destinado à programação da licença-maternidade mediante concessão de incentivo fiscal, e altera a Lei $n^{\circ}$ 8.212, de 24 de julho de 2001.

Ministério do Desenvolvimento e Combate à Fome. Disponível em: http://www.mds.gov.br/bolsafamilia. Acesso em 06 de maio de 2013.

COPATTI, Lívia Copelli. O Conselho de Direitos da Criança e do Adolescente e os Instrumentos de Participação Social para a Garantia de direitos no Município de Sananduva. Dissertação (mestrado) - Pós-Graduação em Direito - Mestrado, Área de Concentração em Direitos Sociais e Políticas Públicas, Universidade de Santa Cruz do Sul, Santa Cruz do Sul, 2011.

CUSTÓDIO, André Viana. Direito da criança e do adolescente. Santa Catarina. Ed. Unesc. 2009.

DIAS, Maria Berenice. Manual de direito das famílias. 8.ed.rev. e atual. São Paulo: Editora Revista dos Tribunais, 2011.

GRUPO DE TRABALHO DO MINISTÉRIO PÚBLICO FEDERAL, PROCURADORIA FEDERAL DOS DIREITOS DO CIDADÃO. Manual de atuação: Direito Humano á alimentação adequada. Disponível em:

http://www.prsp.mpf.gov.br/prdc/areadeatuacao/deconsoccult/Manual\%20de\%20Atuacao\%2 $0 \% 20$ Direito $\% 20$ Humano $\% 20$ a\%20Alimentacao\%20Adequada.PDF. Acesso em 06 de maio de 2013.

INSTITUTO BRASILEIRO DE ANÁLISES SOCIAIS E ECONÔMICAS - IBASE. MENEZES, Francisco; SANTARELLI, Mariana. Da Estratégia Fome Zero ao Plano Brasil Sem Miséria: elementos da seguridade social no Brasil. Disponível em: http://www.ibase.br/pt/wp-content/uploads/2013/02/proj-fomezero.pdf. Acesso em 22 de março de 2014.

KRELL, Andreas. Direitos Sociais e controle judicial no Brasil e na Alemanha. Porto Alegre: Editor Sérgio Antônio Fabris, 2002.

LANE, Renata. Direito à alimentação. in IKAWA, Daniela; PIOVESAN Flávia e FACHIN, Melina Girardi Fachin (Org). Direitos humanos na ordem contemporânea: proteção nacional, regional e global. Curitiba: Editora Juruá, 2010.

LEIVAS, Paulo. In: Relatório Final do Seminário "A exigibilidade do Direito Humano à Alimentação Adequada e o Sistema Nacional de Segurança Alimentar e Nutricional”. Disponível em: http://www.fao.org/fileadmin/user_upload/righttofood/docs/seminario\%20relatorio\%20final\% 20maio\%202010.pdf. Acesso em 20 de março de 2014.

MALUF, Renato. Ações públicas Locais de Segurança Alimentar Nutricional - Diretrizes para uma Política Municipal. São Paulo, POLIS, 2000.

MENEZES, Francisco. A fome nos dados do IBGE. Jornal do Brasil. 31 de janeiro de 2005. Disponível em: 
http://www.gvces.com.br/index.php?r=noticias/view\&id=16810\&0\%5Bidioma_id\%5D=\&0\% 5Bidnoticia $\% 5 \mathrm{D}=\& 0 \% 5 \mathrm{Bidusuario} \% 5 \mathrm{D}=\& 0 \% 5 \mathrm{Btitul0} \% 5 \mathrm{D}=\& 0 \% 5 \mathrm{Btexto} \% 5 \mathrm{D}=\& 0 \% 5 \mathrm{Bdata}$ cad $\% 5 \mathrm{D}=\& 0 \% 5 \mathrm{Bdatapub} \% 5 \mathrm{D}=\& 0 \% 5 \mathrm{~B}$ publicado $\% 5 \mathrm{D}=1 \& 0 \% 5 \mathrm{~B}$ fonte $\% 5 \mathrm{D}=\& 0 \% 5 \mathrm{Bautor} \%$ $5 \mathrm{D}=\& 0 \% 5 \mathrm{Bidfonte} \% 5 \mathrm{D}=\& 0 \% 5 \mathrm{Bidtipo} \% 5 \mathrm{D}=\& 0 \% 5 \mathrm{Bidioma} \% 5 \mathrm{D}=\& 0 \% 5 \mathrm{Burl}$-referencia $\% 5$ $\mathrm{D}=\& 0 \% 5 \mathrm{Bdestaque} \% 5 \mathrm{D}=1$. Acesso em 09 de maio de 2013.

ORGANIZAÇÃO DAS NAÇÕES UNIDAS. Declaração de Genebra dos Direitos da Criança. 1924. Disponível em:

http://198.106.103.111/cmdca/downloads/Declaracao_de_Genebra_Direitos_da_Crianca.pdf. Acesso em 13 de junho de 2012.

Convenção Sobre os Direitos da Criança, 1989. Disponível em:

http://www.unicef.org/brazil/pt/resources_10120.htm. Acesso em 10 de maio de 2013.

Declaração Universal Dos Direitos das Crianças, 1959.Disponível em :

http://198.106.103.111/cmdca/downloads/Declaracao_dos_Direitos_da_Crianca.pdf. Acesso em 10 de maio de 2013.

Organização das Nações Unidas para a Alimentação e a Agricultura. Disponível em:

http://www.fao.org/hunger/hunger-home/es/. Acesso em 07 de maio de 2013

REVISTA EXAME.COM. Disponível em:

http://exame.abril.com.br/mundo/noticias/brasil-doa-25-mil-toneladas-de-arroz-a-cuba.

Acesso em 10 de maio de 2013.

SENNA, Mônica de Castro Maia; BURLANDY Luciene; MONNERAT, Giselle Lavinas; SCOTTZ, Vaness; MAGALHÃES. Rosana. Programa Bolsa Família: nova institucionalidade no campo da política social brasileira? Disponível em: http://www.scielo.br/pdf/rk/v10n1/v10n1a10.pdf. Acesso em 22 de abril de 2012.

SODRÉ, Jorge Irajá Louro. O direito humano à alimentação adequada no rol de direitos fundamentais sociais da constituição federal brasileira e sua exigibilidade frente ao Estado: controle jurisdicional de política pública ou garantia de direito social?

Dissertação (mestrado) - Pós-Graduação em Direito - Mestrado, Área de Concentração em Direitos Sociais e Políticas Públicas, Universidade de Santa Cruz do Sul, Santa Cruz do Sul, 2013.

TRIBUNAL DE JUSTIÇA DE ALAGOAS. Processo n 4.830/07. 28ª Vara Cível da Capital - Infância e Juventude. Juiz de Direito: Fábio José Bittencourt Araújo. Julgado em 10 de setembro de 2007. Disponível em:

http://www.abrandh.org.br/download/20100824233300.pdf. Acesso em 13 de maio de 2013.

TRIBUNAL DE JUSTIÇA DE ALAGOAS. Apelação Cível n. ${ }^{\circ}$ 2008.000779-2 $1^{\text {a }}$ Câmara Cível do Tribunal de Justiça do Estado de Alagoas, Relator: James Magalhães de Medeiros. Julgado em 25 de agosto de 2010

VALENTE, Flavio Luiz Schieck. Direito Humano à alimentação. São Paulo: Editora Cortez, 2002. 
VIGNA, Edélcio. Direito Humano à Alimentação Adequada e Orçamento Público. In POVESAN, Flavia. CONTI, Irio Luiz (Org). Direito Humano à Alimentação Adequada. Rio de Janeiro: Editora Lumen Juris, 2007. 237-253 p.

ZIMMERMANN, Clóvis. As Políticas Públicas e a Exigibilidade do Direito Humano à Alimentação. In PIOVESAN, Flávia. CONTI, Irio Luiz (Org). Direito Humano à Alimentação. Rio de Janeiro: Editora Lumen Juris, 2007. 255-279 p. 